\title{
UMA PROPOSTA DE FOMENTO À SALVAGUARDA DO PATRIMÔNIO PALEONTOLÓGICO DA PRAIA DO ATALAIA, PARÁ, BRASIL
}

\author{
Leonardo de Souza Silva \\ Museologia, Universidade Federal do Pará \\ leosilvaufpa@gmail.com
}

Sue Anne Regina Ferreira da Costa

Museologia, Universidade Federal do Pará

sue.costa@gmail.com

\begin{abstract}
RESUMO
A região amazônica, no Brasil, possui o patrimônio natural reconhecido, porém outros ecossistemas ocuparam a região e estão registrados em rochas, como as da Formação Pirabas, na região litoral do Pará, na praia do Atalaia (Salinópolis). Os fósseis destas rochas detêm potencial social transformador quando bem usufruídos. E buscamos em sites, bibliotecas e 150 entrevistas, conhecimentos referentes a estes, para problematizar, a partir de diferentes áreas, o (re)conhecimento deste patrimônio na região. Há fragilidades na relação entre as informações acadêmicas e como estas estão disponibilizadas ao público, dificultando, assim, a preservação e a utilzação social dos fósseis. Entretanto, sugerimos políticas públicas e um museu no município, como ações que podem minimizar tal situação.
\end{abstract}

Palavras-chaves: Fósseis. Salinópolis. Museu.

\section{A PROPOSAL TO PROMOTE SAFEGUARD OF THE PALEONTOLOGICAL HERITAGE OF THE BEACH OF ATALAIA, SALINÓPOLIS, PARÁ, BRAZIL}

\begin{abstract}
The Amazon region, in Brazil, has the recognized natural heritage, but other ecosystems have occupied the region and are recorded in rocks, such as the Pirabas Formation, in the coastal region of Pará, Atalaia beach (Salinópolis). The fossils of these rocks have transformative social potential when well enjoyed. And we searched in websites, libraries and 150 interviews, knowledge related to these, to problematize, from different areas, the (re) knowledge of this patrimony in the region. There are weaknesses in the relationship between academic information and how it is made available to the public, thus hindering the preservation and social use of fossils. However, we suggest public policies and a museum in the municipality, as actions that can minimize this situation.
\end{abstract}

Keywords: Fossils. Salinópolis. Museum.

UNA PROPUESTA DE FOMENTO A LA SALVAGUARDIA DEL PATRIMONIO PALEONTOLÓGICO DE LA PLAYA DEL ATALAIA, SALINÓPOLIS, PARÁ, BRASIL

\section{RESUMEN}


La región amazónica, en Brasil, posee el patrimonio natural reconocido, pero otros ecosistemas ocuparon la región y están registrados en rocas, como las de la Formación Pirabas, en la región litoral de Pará, en la playa de Atalaia (Salinópolis). Los fósiles de estas rocas tienen potencial social transformador cuando están bien disfrutados. Y buscamos en sitios, bibliotecas y 150 entrevistas, conocimientos referentes a estos, para problematizar, desde diferentes áreas, el (re) conocimiento de este patrimonio en la región. Hay fragilidades en la relación entre las informaciones académicas y cómo éstas están disponibles al público, dificultando así la preservación y la utilización social de los fósiles. Sin embargo, sugerimos políticas públicas y un museo en el municipio, como acciones que pueden minimizar tal situación.

Palavras clave: Fósiles. Salinópolis. Museo.

\section{UNE PROPOSITION DE PROMOTION POUR LA SAUVEGARDE DU PATRIMOINE DE PALÉONTOLOGIQUE ATALAIA BEACH, SALINÓPOLIS, PARÁ, BRÉSIL}

\section{RÉSUMÉ}

La région amazonienne, au Brésil, possède le patrimoine naturel reconnu, mais d'autres écosystèmes ont occupé la région et sont enregistrés dans des roches, comme la Formation de Pirabas, dans la région côtière de Pará, sur la plage Atalaia (Salinópolis). Les fossiles de ces roches ont un potentiel social transformateur lorsqu'ils sont bien appréciés. Et nous avons cherché dans des sites web, des bibliothèques et 150 entretiens, des connaissances liées à celles-ci, à problématiser, à partir de différents domaines, la (re) connaissance de ce patrimoine dans la région. Il y a des faiblesses dans la relation entre l'information académique et la façon dont elle est mise à la disposition du public, entravant ainsi la préservation et l'utilisation sociale des fossiles. Cependant, nous suggérons des politiques publiques et un musée dans la municipalité, comme des actions qui peuvent minimiser cette situation.

Mots-clés: Fossiles. Salinópolis. Musée.

\section{INTRODUÇÃO}

A conotação de patrimonio natural é apresentada na literatura contemporânea como proeminente de debates recentes, como por exemplo, a conferência do ano de 1972, realizada na França por iniciativa da Organização das Nações Unidas para a Educação, Ciência e Cultura (Unesco), que surge como um marco ao definir monumentos naturais, físicos e/ou biológicos como bens de potencial contemplativo e cientifico capazes de desvendar parte do passado da vida e formação da terra (DELPHIM, 2009; PONCIANO et al., 2013; UNESCO, 1972).

Nesse contexto, cria-se subgrupos em torno da fauna e da flora, que permitem perspectivas patrimoniais para os fósseis, uma vez que se caracterizam como documentos que registram a vida 
de seres que em algum momento passaram pelo planeta (BARRETO et al., 2013). São amparados legalmente por poucas e deficitárias leis (p.e GADENS-MARCON et al., 2014; SOARES et al., 2014), insuficientes para resguardá-los de práticas antrópicas não científicas como o comércio ilegal e o vandalismo, carecendo então de aprimoramentos - de preferência - organizados em conjunto por Estado, meios de comunicação, instituições, educadores e população, visando benefícios em torno de um bem não renovável (DIAS et al., 2003; LEITE DO NASCIMENTO et al., 2008; PONCIANO et al., 2013; SANTOS, CARVALHO, 2007; SCIFONI, 2006; SOUZA et al., 2007).

\section{CONTEÚdO PALEONTOLÓGICO DA AMAZÔNIA: CONHECENDO A FORMAÇÃO PIRABAS}

Inclusa nesse contexto, temos a região amazônica, que se destaca ao conter formações geológicas com registros do Paleozóico, Mesozóico e Cenozóico (COSTA et al., 1996; RAMOS, 1986). Uma delas é a Formação Pirabas, que está presente nos Estados do Maranhão, Piauí e Pará - neste último há o maior destaque, pois contém 21 dos 27 sítios fossilíferos que a compõem -, e que se qualifica como o maior depósito de vestígios fósseis do Cenozóico marinho brasileiro (TÁVORA, SANTOS, ARAÚJO, 2010a; TÁVORA, SANTOS, NOGUEIRA NETO, 2010b).

Em seu conteúdo paleontológico, há resquícios de seres invertebrados como moluscos bivalves e gastrópodes, e também vertebrados tais como crocodilianos, tubarões e peixes-boi (Figura 1), que são coletados e estudados por cientistas desde o século XIX (p.e. BARBOSA, 1958; COSTA et al., 2004; FERREIRA PENNA, 1876; FERREIRA, CUNHA, 1957; TOLEDO et al., 1997; TOLEDO, DOMNING, 1989), porém, pouco trabalhados pela mídia paraense, ficando restritos ao âmbito universitário e museológico, ainda que completem aréas de influência econômica e turística do Estado do Pará (KALIFE, 2013; OLIVEIRA JUNIOR, 2014; SILVA, SILVA, COSTA, 2015a). 
Figura 1: Costelas de Peixes-bois encontradas na Praia do Atalaia, Salinópolis - PA.

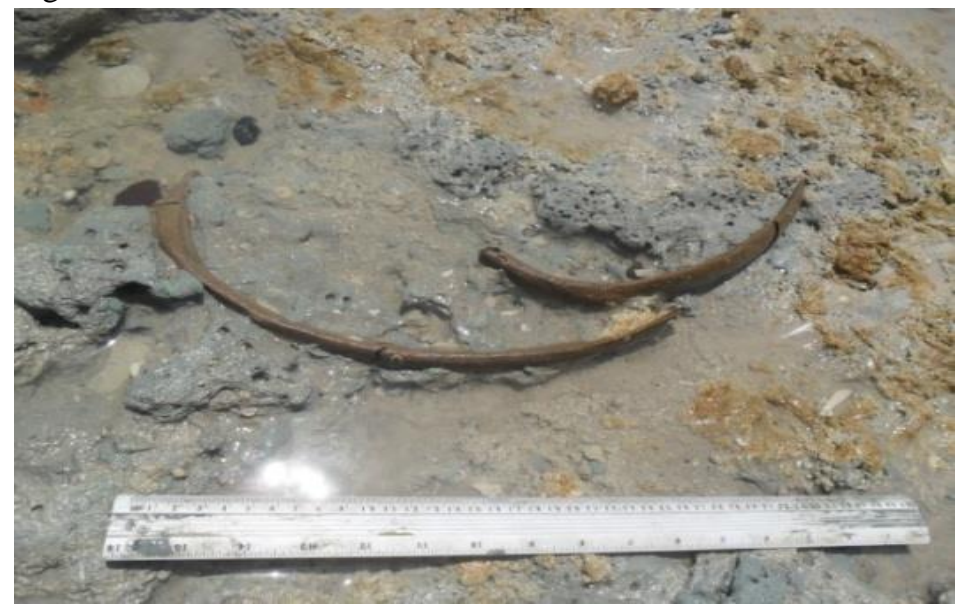

Foto: Sue Costa, 2013.

Exemplo disso é a Praia do Atalaia (Figura 2), que, pesquisada pelo seu conteúdo paleontológico desde a década de 50 do século XX, está a cerca de $220 \mathrm{~km}$ da capital Belém, no município de Salinópolis (Figura 3) e se caracteriza como um dos balneários mais populosos do estado, principalmente, através de um turismo que se desenvolve anualmente e de forma ambientalmente inadequada, inclusive, comprometendo os fósseis que são pouco protegidos e comunicados para a sociedade (BARBOSA, 1958; GREGORIO, MENDES, BUSMAN, 2005; RANIERI, EL-ROBRINI, 2016; SILVA, SILVA, COSTA, 2015a).

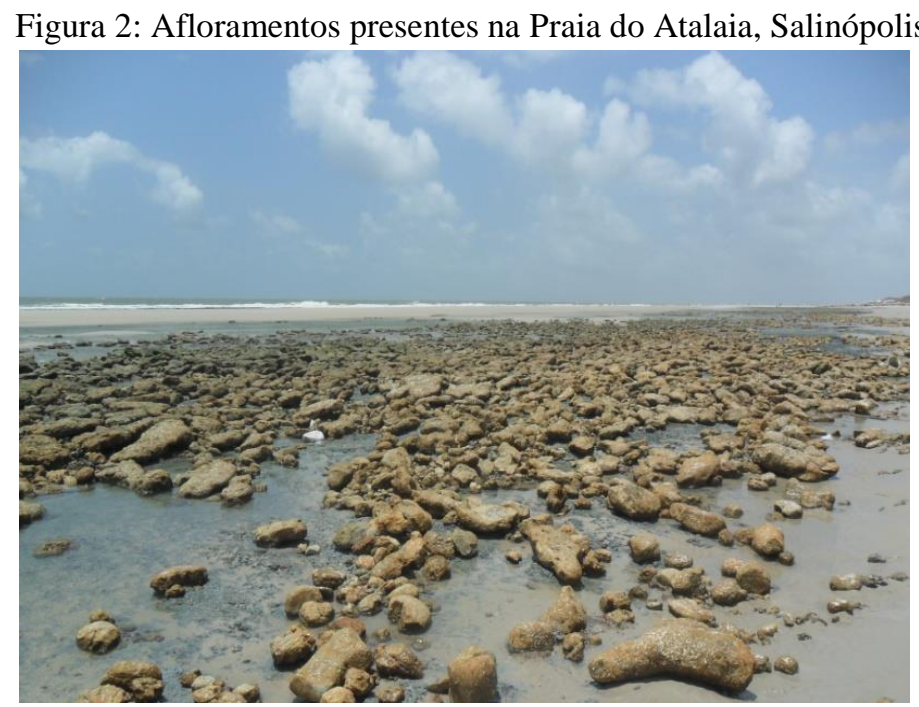

Foto: Sue Costa, 2013. 
Figura 3: Mapa de localização de Salinópolis.

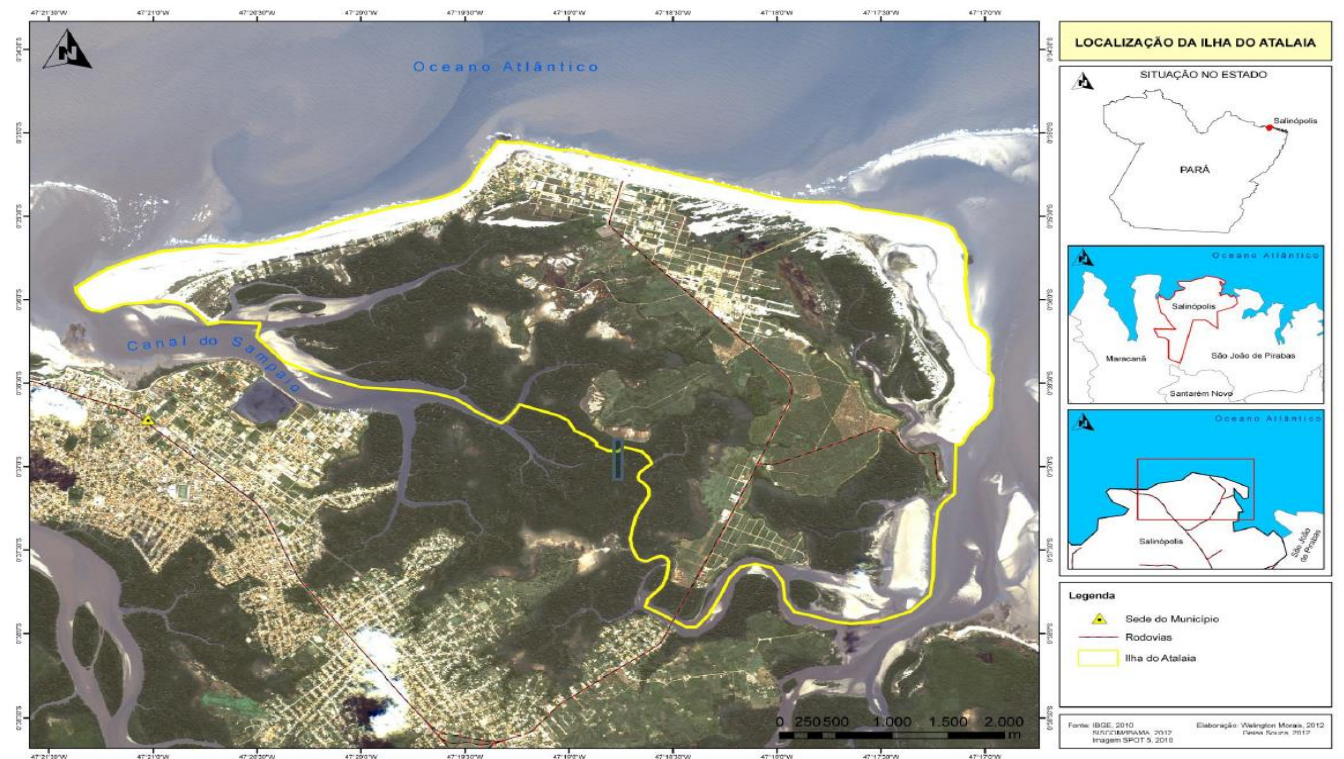

Fonte: Souza (2012, p. 39).

Além disso, em contraposição aos outros 2 principais sítios paleontológicos do estado do Pará, a região contém poucos atravessamentos, pois não é tombada, como a Mina B-17, em Capanema, e não contém práticas religiosas, como as da Ilha de Fortaleza, em São João de Pirabas, caracterizando-se, então, como um espaço mais democrático e de outros usos públicos (RANIERI, EL-ROBRINI, 2016; SILVA, 2007; SILVA, SILVA, COSTA, 2015 a e b).

\section{DOS MEIOS DE COMUNICAÇÃO A PROPOSTA DE SALVAGUARDA}

Considerando a atualidade do tema e a ausência de políticas públicas que o contemplem, compreende-se como necessário averiguar a participação de meios de comunicação cientifica, capazes de ampliar o campo de alcance dos estudos até então realizados, ao informar a população que não vivencia constantemente o espaço acadêmico ou as áreas nas quais os fósseis se encontram (BEVORT, BELLONI, 2009; SILVA, SILVA, COSTA, 2015b; UNESCO, 1972).

Aproximá-los, seja da população nativa ou transitória (DELPHIM, 2009; VILAS-BOAS, BRILHA, LIMA, 2013), representa uma atitude primária para atentar e sensibilizar o grande público contemporâneo sobre a importância de salvaguardar e usufruir com qualidade de seus benefícios, que por consequência, ficará como legado para as gerações provindouras (BARRETO et al., 2013; NASCIMENTO, RUCHKYS, MANTESSO NETO, 2008). 
Por conseguinte, é bem-vindo analisar a presença desse conteúdo em meios acadêmicos e midiáticos de informação (TÁVORA, SANTOS, NOGUEIRA NETO, 2010b), assim como o grau de (re)conhecimento que a população vigente, dos grandes centros, possui sobre os sítios fossilíferos dispersos ao longo do estado do Pará, em especial., da Praia do Atalaia (TÁ VORA, SANTOS, ARAÚJO, 2010a), para que possamos propor medidas de salvaguarda, as quais procurem se aprofundar na importância de também levar ao público esse patrimônio, que é, muitas vezes, esquecido quando se debate a preservação e a valorização da natureza (CASTRO, 2009).

\section{METODOLOGIA UTILIZADA}

Com o propósito de compreender, inicialmente, os conhecimentos envolvendo esse patrimônio, foram utilizadas duas metodologias, por meio de dois momentos expostos abaixo:

1) Acadêmico, no qual abordamos quatro (4) bibliotecas e oito (8) ambientes virtuais, como: sites, repositórios e portais vinculados a instituições, órgãos de pesquisa, contribuidores para a divulgação científica e/ou salvaguarda desse patrimônio, como por exemplo, a Universidade Federal do Pará (UFPA), o Museu Paraense Emílio Goeldi (MPEG), a Companhia de Pesquisa de Recursos Minerais (CPRM), a Sociedade Brasileira de Paleontologia (SBP), a Sociedade Brasileira de Geologia (SBG), e, ainda, foram pesquisados os Periódicos da Coordenação de Aperfeiçoamento de Pessoal de Nível Superior (Capes) e o Scientific Electronic Library Online Brazil (Scielo Brasil);

2) O segundo momento envolveu o senso comum, quando 150 pessoas foram entrevistadas por meio de questionários fechados, com perguntas referentes a diversas tipologias patrimoniais, e questionamentos sobre conhecimentos gerais e específicos acerca do patrimônio paleontológico de Salinópolis, com o intuito de apresentar o grau de conhecimento de parte da população urbana de Belém sobre o tema academicamente e midiaticamente pesquisado por nós, uma vez que esses sujeitos compõem, majoritariamente, o principal grupo de turistas frequentadores dos balneários do município.

As entrevistas ocorreram em diferentes locais da capital, como o Parque do Museu Paraense Emílio Goeldi, o Bosque Rodrigues Alves, a Praça da República e a Universidade Federal do Pará. 


\section{O PATRIMÔNIO PALEONTOLÓGICO DA FORMAÇÃO PIRABAS: DA ACADEMIA AO SENSO COMUM BELENENSE}

\section{O conhecimento da Formação Pirabas no meio acadêmico}

Partindo desse princípio, como resultados iniciais da busca, encontramos 308 publicações relacionadas à Formação Pirabas (Quadro 1).

Quadro 1: Publicações encontradas (OBS: Não foram considerados possíveis boletins da Universidade Federal do Pará, devido à necessidade prévia do nome do arquivo).

\begin{tabular}{|l|c|}
\multicolumn{1}{|c|}{ Locais pesquisados } & $\begin{array}{c}\text { Quantidade de informações } \\
\text { encontradas }\end{array}$ \\
\hline Biblioteca Arthur Vianna & 1 \\
\hline Biblioteca do MPEG & 36 \\
\hline Biblioteca Central da UFPA & 3 \\
\hline Biblioteca do IG UFPA & 10 \\
\hline Repositório Online da UFPA & 5 \\
\hline Repositório Online do MPEG & 14 \\
\hline Repositório SCIELO & 2 \\
\hline Portal CAPES & 20 \\
\hline Portal de Revistas da UFPA & 0 \\
\hline Site do CPRM & 167 \\
\hline Site da SBP & 29 \\
\hline Site da SBG & 21 \\
\hline Total & 308 \\
\hline Fonte: Os autores, & \\
\hline
\end{tabular}

Fonte: Os autores, 2018.

Dessas informações, 270 provêm do meio digital, e apenas 38 estão disponibilizadas para consulta física/ presencial.

Meios como os repositórios on-line da Universidade Federal do Pará (UFPA), do Museu Paraense Emílio Goeldi (MPEG) e do Scientific Electronic Library Online Brazil (Scielo Brasil), devido a seus princípios e fins, repassam uma maior confiança ao pesquisador, em um momento no qual a sociedade está diretamente conectada a uma realidade virtual, na qual várias informações podem ser inseridas, descarregadas, copiadas e impressas sem custo por qualquer pessoa, mesmo 
que, às vezes, alguns conteúdos estejam disponíveis de forma errada e/ou confusa, viabilizando análises e opiniões precipitadas (EHRENBERG, GALINDO, 2010; PORTO, BROTAS, BORTOLIERO, 2011; SIEBRA, OLIVEIRA, MARCELINO, 2014; SILVA, 2015).

Porém, na prática, poucos têm contribuído realmente para a difusão da informação sobre a Formação Pirabas, uma vez que somente o site do Serviço Geológico do Brasil - Companhia de Pesquisa de Recursos Minerais (CPRM), que, segundo Schobbenhaus e Silva (2012), faz parte das onze entidades que representam a Comissão Brasileira de Sítios Geológicos e PaleobiológicosSIGEP, criada em 1997, para colaborar na conservação do patrimônio geológico nacional, por meio do levantamento, descrição, publicações e/ou implantações de geoparques, apresentou grandes resultados.

Nota-se que o mesmo, ao somarmos os resultados de todos os meios pesquisados, tem 167 das publicações, ou seja, mais da metade do conteúdo total, enquanto que ambientes virtuais, de origem local, como o repositório do Museu Paraense Emílio Goeldi (MPEG) tem apenas 14 produções relacionadas à Formação Pirabas, quantidade tímida, se considerarmos não somente o acervo bibliográfico da instituição, mas também sua fundação em 1895, e sua relevância para a salvaguarda dos próprios fósseis, uma vez que o Museu contém um acervo superior a 2500 registros fósseis somente dessa unidade geológica (OLIVEIRA JUNIOR, 2014; SANJAD, 2007).

Essa realidade poderia ser contraposta a partir da consulta física em instituições científicas e literárias como os museus e bibliotecas selecionados por nós, porém, confirma-se ainda mais a deficiência de informações, uma vez que locais de leitura como a tradicional Biblioteca Pública Arthur Vianna, a Biblioteca do Museu Paraense Emílio Goeldi (MPEG), e as bibliotecas Central e do Instituto de Geociências da Universidade Federal do Pará (UFPA), possuem poucas bibliografias disponíveis para consulta.

Na primeira, há apenas uma (1) publicação envolvendo a geologia da Formação Pirabas. Trata-se do livro “A Formação Pirabas: Sua evolução e interpretação”, publicado em 1976 por Fritz Louis Ackermann.

Já na Biblioteca do Museu Paraense Emílio Goeldi, foram encontradas em meio a sua coleção, 36 publicações, sendo 35 artigos publicados no boletim de Ciências Naturais do próprio Museu, e somente uma dissertação de Mestrado, intitulada "A comunidade de Tubarões (Chondrichthyes: selachii: Galea) da Formação Pirabas, Neógeno da Amazônia oriental", apresentada por Sue Anne Regina Ferreira da Costa, no ano de 2005. 
Por último, têm-se as bibliotecas universitárias do campus Guamá da Universidade Federal do Pará, escolhidas por estarem vinculadas a um âmbito sumariamente acadêmico. A Biblioteca Central da Universidade Federal do Pará (UFPA) possui um acervo superior a 5.000.000 volumes, 190.000 títulos em humanidade e coleções ligadas às mais diversas áreas de conhecimento, enquanto que a Biblioteca do Instituto de Geociências (IG) é composta por um acervo, a grosso modo, voltado para às Geociências (PIRES; GIRARD, 2014).

Somando esses dois espaços literários, têm-se um total de 13 publicações vinculadas ao tema pesquisado, três (3) presentes na Biblioteca Central (BC), sendo duas (2) dissertações de mestrado e um (1) artigo; e 10 disponíveis na Biblioteca do Instituto de Geociências (IG), por meio de seis (6) dissertações de Mestrado e quatro (4) teses de Doutorado.

Ao fim desse levantamento, ao analisarmos somente as publicações relacionadas à Praia do Atalaia, encontramos apenas quatro (4) informações, conforme mostra o quadro 2:

Quadro 2: Publicações presentes nos âmbitos pesquisados (OBS: Não foram considerados possíveis boletins da Universidade Federal do Pará, devido à necessidade prévia do nome do arquivo, e também foram desconsiderados os dados do CPRM, pois muitos não têm títulos).

\begin{tabular}{|c|c|}
\hline Local em que se encontra a publicação & Número de publicações encontradas \\
\hline Biblioteca do IG UFPA & 1 \\
\hline Site da SBG & 2 \\
\hline Site da SBP & 4 \\
\hline Total & 1 \\
\hline
\end{tabular}

Fonte: Os autores, 2018.

Explicitando em números, dentre os dados adquiridos, constatamos que, das 308 publicações encontradas, apenas quatro (4) possuem título diretamente ligado ao município de Salinópolis, onde ainda não há ações de salvaguarda como o tombamento (SILVA, SILVA, COSTA, 2015 a e b; SILVA, 2007). Esses resultados preocupam, pois a ausência de maiores informações colabora para que o conhecimento sobre os fósseis se restrinja a profissionais do corpo acadêmico, que possuam o interesse pelo tema, e a possibilidade de pesquisá-lo profundamente nas mais diversas plataformas e estabelecimentos ligados ao ensino e proteção do patrimônio.

\section{A Formação Pirabas na perspectiva do senso comum belenense}


É levando em consideração esses dados e sabendo que ainda é ínfima a quantidade de trabalhos envolvendo a noção patrimonial do público em espaços inerentes ao âmbito acadêmico, que, pensando na Praia do Atalaia e seu conteúdo paleontológico, aplicamos questionários com indivíduos distintos, pois esse método permite que as perguntas sejam feitas e respondidas com a maior linearidade possível, ou seja, sem disparidades (AGUIAR, MEDEIROS, 2009; CASTRO, MANSUR, CARVALHO, 2015). Além de também, resguardar dados com informações externas às bibliografias científicas (CASTRO; MANSUR; CARVALHO, 2015).

Dentre os resultados adquiridos, o primeiro (Gráfico 1) apresenta que ocorreu uma desproporção muito grande na faixa etária do público que frequenta os grandes espaços públicos de Belém. Afinal, de 150 entrevistados, 18 deles encontram-se na faixa dos 5 aos 15 anos, adequando-se à chamada "geração Z”, que, conforme Kampf (2011), são os nativos digitais, ou seja, aquele grupo de indivíduos que nasceram em um momento no qual a internet e seus artifícios já estavam estabelecidos no cotidiano humano a partir do convívio social e educacional, encontrando, então, menos dificuldades de uso e acesso a novas tecnologias, plataformas e novidades, se comparados com as demais gerações.

Dentre os demais, 79, ou seja, mais da metade, pertencem à “geração NET”, pois possuem entre 16 e 26 anos de idade e, segundo Tapscott (1999) e Ehrenberg e Galindo (2010), possuem acessos diários à internet, criando laços, adquirindo e expondo informações que os notabilizam como um público jovem e antento ao seu entorno.

E, por fim, ao compactarmos um terceiro público, encontramos 53 pessoas com faixa etária de 27 a 70 anos, que, segundo Ehrenberg e Galindo (2010) e Santos (2010), são indivíduos que obtiveram o primeiro contato com o mundo virtual e/ou vivenciaram o ápice do jornal impresso no Brasil, logo, jamais foram desprovidos de meios de comunicação e informação.

Gráfico 1: Faixa etária do público entrevistado. 


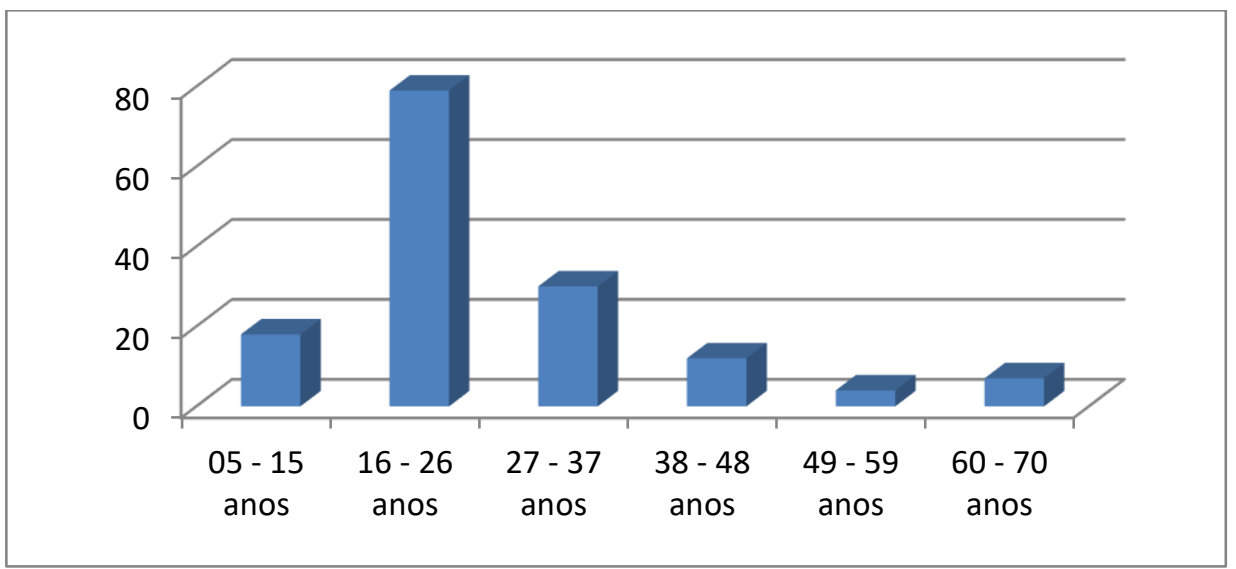

Fonte: Os autores, 2018.

Entretanto, para investigar o que este público (re)conhece como patrimônio, e se o sítio paleontológico da Praia do Atalaia está presente nessa apreensão, primeiro exibimos para os questionados, um conjunto de 10 palavras de múltipla escolha, ligadas a tipologias patrimoniais distintas, como o geológico, o biológico, o paisagístico, o econômico, o arquitetônico e o gastronômico, a modo de ampliar a ideia de patrimônio dos entrevistados, a partir de uma perspectiva do senso comum, que, segundo Silva (2011), trata-se do conhecimento repentino, ou seja, pautado em opiniões, como ocorre em entrevistas à base de questionários.

Dentre as respostas, poucas alternativas obtiveram índices semelhantes ou superiores a 14\%, ou seja, foram mencionadas por mais da metade dos entrevistados (Gráfico 2). São elas: Obras de Arte (15\%), Árvores (14\%) e Praças (14\%). Enquanto que, dentre os menos citados, destacam-se os Minérios (7\%), Rochas (4\%) e Dinheiro (3\%).

Gráfico 2: Percentual das alternativas selecionadas como patrimônio pelos entrevistados.

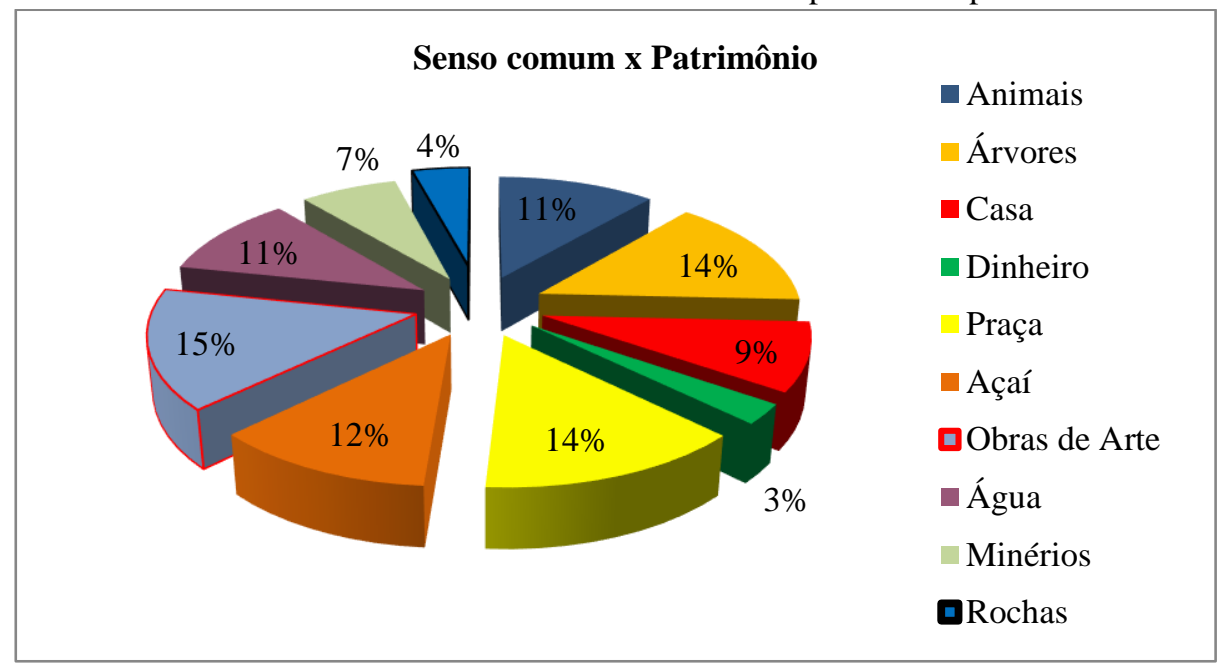

Fonte: Os autores, 2018. 
A partir desses percentuais, percebe-se que construções humanas, como as Obras de Arte e as Praças, estão bem representadas, principalmente se comparadas a elementos ligados ao patrimônio natural, haja vista que, com exceção da alternativa árvores, todas as outras foram mencionadas por menos de $44 \%$ dos entrevistados, sendo ainda mais preocupantes se considerarmos somente o patrimônio natural geológico, uma vez que menos de $35 \%$ dos entrevistados compreendem rochas e minérios como patrimônio, respectivamente, há $4 \%$ e $7 \%$ de respostas selecionadas.

Esses índices, se considerarmos que a compreensão de patrimônio de um determinado público está diretamente ligada à experiência de vida e ao contato que esse apresenta para com elementos distintos (PONCIANO; MACHADO; CASTRO, 2013), evidencia, segundo Brilha (2004), a falta de divulgação de um conhecimento técnico-científico relacionado à área das ciências da Terra, e uma apreensão maior da realidade econômica, uma vez que os minérios, que são utilizados principalmente na produção do cimento que constrói a maioria das residências urbanas, apresentam maior percentual, mesmo provindos de uma atividade mineradora, que tem desacordos com a conservação da natureza e modifica o cotidiano das populações de seu entorno em meio a interesses políticos e econômicos sobre esse patrimônio (GESICKI, SANTUCCI, 2011; SANTOS, CARVALHO, FERNANDES, 2010; SANTOS, ESTERCI, 2016).

É nessa realidade que se encontra o patrimônio paleontológico do estado do Pará, em específico da Praia do Atalaia, em Salinópolis, que devido a sua ligação direta com o patrimônio geológico (BENTO; RODRIGUES, 2010), foi alvo de três (3) perguntas do questionário. Dessa vez, quando questionados sobre a existência de fósseis no estado do Pará, os resultados apresentam frequências inferiores a 50\% do total de entrevistados (Gráfico 3).

Gráfico 3: Percentual de pessoas que já ouviram falar sobre fósseis no Pará.

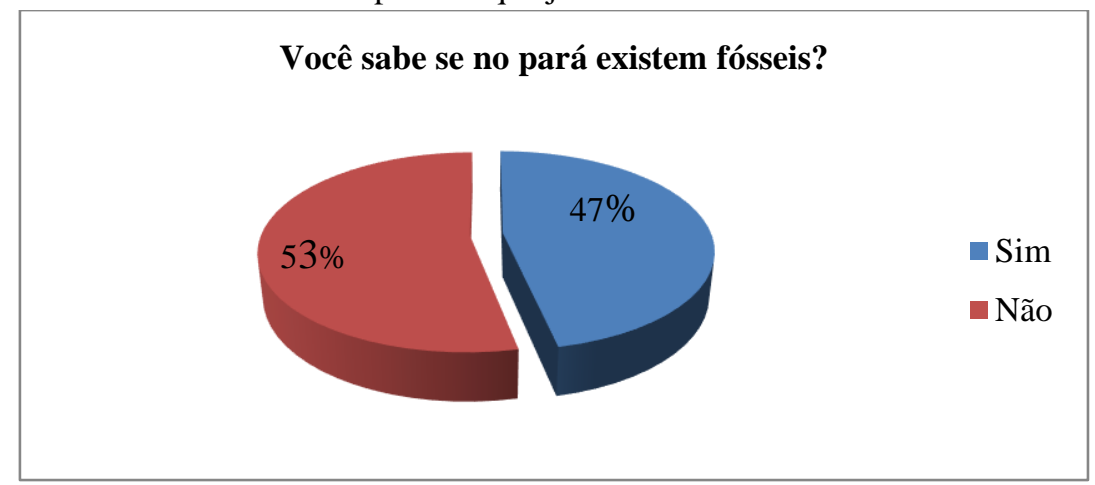

Fonte: Os autores, 2018. 
Quando questionamos esse público que respondeu positivamente, sobre onde seria possível encontrar fósseis no estado, obtivemos 86 possíveis locais, sendo que desses, em 22 resultados, os entrevistados não se recordavam ou não sabiam pontuar um local específico. Já em outras 15 afirmações, foram indicadas opções como áreas remotas, interiores e sul do estado do Pará, reafirmando, então, que há uma falta de comunicação entre as pesquisas realizadas no âmbito acadêmico e a população como um todo, principalmente quando estas envolvem a noção de natureza como patrimônio (PONCIANO, MACHADO, CASTRO, 2013; SILVA, SILVA, COSTA, 2015a).

A partir dos dados coletados, convém destacar que, em 10 oportunidades, temos a presença de áreas como Marajó, Santarém e Monte Alegre, que são áreas reconhecidas por seus vestígios e/ou registros arqueológicos (p.e. BEZERRA, 2011; PEREIRA, 2014; SYMANSKI, GOMES, 2012). Isso nos leva a inferir que, para o senso comum, há relações equivocadas entre os objetos e o tempo de estudo das duas ciências, ou seja, Paleontologia e Arqueologia. Fato que, segundo Silva (2015), é fortalecido pelos próprios meios de comunicação presentes em nossa sociedade, pois informações confusas e não científicas são difundidas e acessadas cotidianamente a partir de livros, jornais, revistas e, principalmente, pela internet.

Como exemplo prático de informações confusas, temos a matéria "Geólogo descobre fósseis em Salinas", difundida no dia 28 de dezembro de 2014 pelo jornal "O Liberal”, encontrada e apresentada por Silva et al. (2015a) como uma notícia de conteúdo precipitado, a começar, em seu título, uma vez que aponta para a descoberta de fósseis na região, dando a entender que é algo recente, quando, cientificamente, há várias pesquisas anteriores e registros salvaguardados pelo Museu Paraense Emílio Goeldi (MPEG), ao longo de seus 151 anos de existência (p.e. BARBOSA, 1958; OLIVEIRA JUNIOR, 2014; SANJAD, 2007).

Além disso, a reportagem não evidenciou se o geólogo envolvido possuía autorização para realizar a coleta, apesar de citar a lei de número 4.146, do ano de 1942, que dá abertura para que universidades e museus realizem tais pesquisas (GESICKI; SANTUCCI, 2011). Informações confusas que podem ocasionar o incentivo ou o aumento de coleções particulares e ações antrópicas negativas, como coletas para a comercialização ilegal, uma vez que esses meios de informação em massa abrangem um grande público em um pequeno intervalo de tempo, o que é problemático, pois, ao mesmo tempo que têm potencial para informar, têm para influenciar alguns indivíduos 
(OLIVEIRA JUNIOR, 2014; PONCIANO, MACHADO, CASTRO, 2013; SILVA, BARRETO FILHO, 2011).

Dentre os locais pontuados como detentores de vestígios fósseis pelos entrevistados, o município de Salinópolis, objeto dessa pesquisa e local da matéria anterior, é o único que pertence à Formação Pirabas (TÁVORA; SILVEIRA; MILHOMEM NETO, 2007), porém, a partir das respostas presentes na tabela 4 , observamos que a localidade é amplamente reconhecida como um dos principais atrativos turísticos do estado, a partir do momento em que, aproximadamente, 55\% dos entrevistados afirmaram tê-la visitado alguma vez na vida (ver Gráfico 4). Enquanto que, em relação aos seus fósseis, atenua-se um grande desconhecimento, haja vista que somente seis (6) dos 150 entrevistados, declararam o município como um espaço detentor desses bens.

Gráfico 4: Relação entre os entrevistados e o município de Salinópolis.

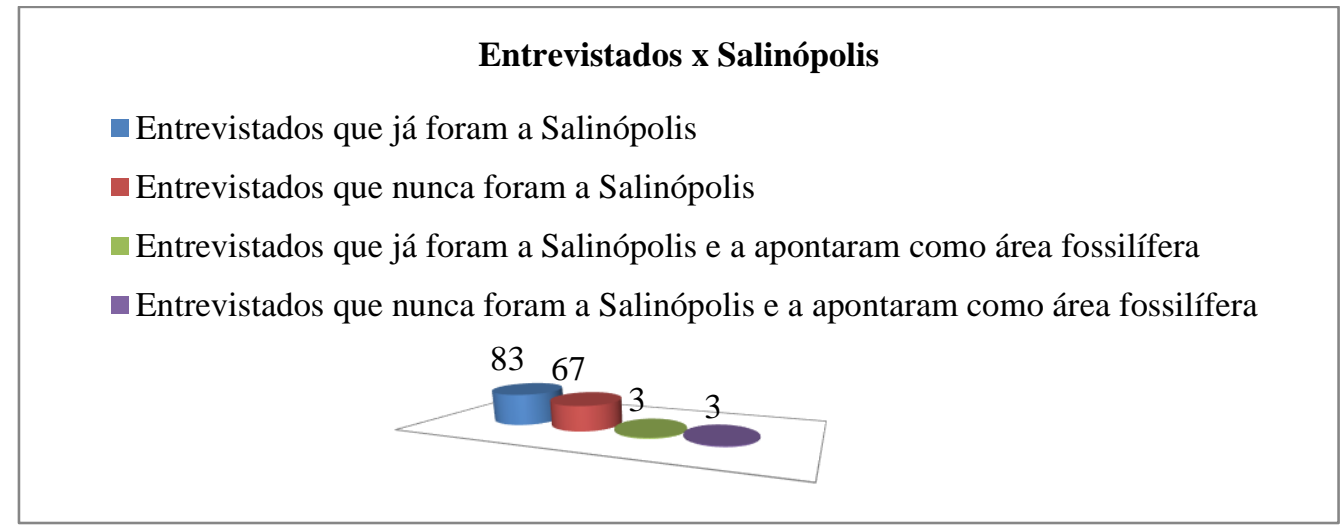

Fonte: Os autores, 2018.

Dessa forma, com esses índices mínimos, percebe-se que esse patrimônio ainda é pouco (re)conhecido e valorizado pela população paraense, em especial a do centro urbano de Belém, local de realização dessas entrevistas. No entanto, é importante ressaltar que a pouca participação da população civil, nesse legado, não se dá somente pela omissão, mas também restrição desse conteúdo a pesquisadores da área. O grande público, em especial, da capital paraense, além de não possuir formação escolar sobre o tema, praticamente não tem acesso a essas informações, e tampouco é incentivado a procurá-las, colaborando para que não conheça e se sinta participante do processo de salvaguarda de um patrimônio natural e cultural, que, teoricamente, é de todos (CARVALHO, ROSA, 2008; CASSETARI, 2011; SILVA, 2015; SILVA, SILVA, COSTA, 2015b; SOARES, 2015).

Com isso, observa-se que os meios de comunicação, sejam físicos ou virtuais, têm deixado a desejar na disseminação informativa desse patrimônio, uma vez que, segundo Jurberg, Gouveia 
e Sousa (2006), possuem papel ativo e inovador para desmistificar um pensamento vago e secular, no qual o saber científico é produzido por e para cientistas, sem considerar a participação da comunidade, criando, então, uma representação da ciência. As mídias deveriam colaborar para a difusão pública desse conhecimento ao apresentar informações, meios, histórias, erros e descobertas do mundo científico.

\section{UMA PROPOSTA DE FOMENTO À SALVAGUARDA DO PATRIMÔNIO PALEONTOLÓGICO DE SALINÓPOLIS}

Doravante as informações encontradas, e considerando que, de acordo com Ribeiro e Iannuzzi (2009), essas áreas se configuram como bens da nação, ou seja, que, teoricamente, pertencem a toda sociedade; e que, segundo Castro (2009), na ausência de leis federais específicas para a salvaguarda, os estados e seus representantes devem, em meio a suas particularidades, procurar formular leis e soluções para os fósseis da região, a modo de ajudar a modificar essa realidade negativa envolvendo o patrimônio paleontológico da Praia do Atalaia, propomos ações de educação patrimonial, em conjunto com a criação de pelo menos uma lei munícipal que assegure essa atividade, assim como a implantação, a médio e longo prazo, de um museu de Paleontologia para o município de Salinópolis, haja vista que não há uma instituição museal na localidade, como se pode comprovar no Cadastro Nacional de Museus (CNM), por meio de sua plataforma virtual Museusbr ${ }^{1}$, para que a salvaguarda dos fósseis retirados dos sítios, pudesse ser mantida na própria cidade.

Primeiramente, para ambas iniciativas, seria necessária a participação de representantes sociais, da Prefeitura Municipal de Salinópolis; do Museu Paraense Emílio Goeldi (MPEG), que atuante na capital Belém, tem consigo, desde 1896, cerca de 4.000 fósseis, 2.500 provenientes da Formação Pirabas, e aproximadamente 730 adquiridos por meio de coletas na Praia do Atalaia (OLIVEIRA JUNIOR, 2014; PÁSSARO, HESSEL, NOGUEIRA NETO, 2014; SANJAD, 2007);

\footnotetext{
${ }^{1}$ Disponível em: http://museus.cultura.gov.br. Acesso em: 04 jan. 2017.
} 
de profissionais formados na área da Museologia, que, em contraponto a atores de outros campos científicos, podem usar de sua criatividade e reflexões para apaziguar especifícamente os problemas entre o patrimônio e a sociedade em que vivemos (BRITTO, 2010; CASTRO, CARVALHO, 2012; SEFIDVASH, 1994); e da comunidade de Salinópolis, que deve ser contemplada, uma vez que, segundo Machado (2008), esses projetos adquirem maiores êxitos quando envolvem pessoas que possuem conhecimentos e relações históricas e tradicionais com o próprio local.

Por conseguinte, esses atores, a partir de debates, encontros, consultas, conferências e demais ações, devem, segundo Guimarães (2004), pensar as formas de valorização e salvaguarda de seu patrimônio natural e cultural. E para tal, pode-se partir de dois princípios:

1) A existência da lei orgânica do Município de Salinópolis ${ }^{2}$.

2) O exemplo do estado do Rio Grande do Sul, que viu a necessidade de se aprofundar na defesa de seu patrimônio paleontológico por meio do aprimoramento de suas leis (CASTRO, 2009).

Salienta-se esse ponto de partida, pois, na Constituíção Brasileira, segundo o advogado da Sociedade Brasileira de Paleontologia (SBP), Rafael de Freitas Valle Dresch (DRESCH, 2006), a principal lei de proteção aos fósseis do país são os artigos 20 e 216, V da Constituição Federal., que os define como patrimônio cultural e natural da união. Além disso, há portarias como a de n. 55/90, que, pelo Ministério de Ciência e Tecnologia (MCT), dá normas às coletas de materiais brasileiros por estrangeiros; e outras leis de fiscalização por parte de órgãos como o Instituto do Patrimônio Histórico e Artístico Nacional (IPHAN) e o Departamento Nacional de Produção Mineral (DNPM), o qual, para Gadens-Marcon, Oliveira e Veneral (2014), são pouco específicas ou de fato aplicadas.

Salinópolis, por exemplo, por meio da portaria n $34 / 2011$, de 29 de setembro de 2011, em sua legislação municipal, traz, como competência comum, ou seja, de responsabilidade do estado e da sociedade, consideráveis 12 tópicos de proteção local, que pertencem ao primeiro princípio destacado nesse trabalho, e do qual podemos pontuar principalmente os itens III, que destaca a importância de zelar por documentos, obras, monumentos, sítios arqueológicos, paisagens e/ou bens de relevância artística, histórica e cultural; o IV, que visa ao fim da evasão, destruição e descaracterização de obras de arte tombadas e de outros bens de potencial artístico,

\footnotetext{
${ }^{2}$ Disponível em: http://www.camarasalinopolis.pa.gov.br/leis.php\#. Acesso em: 04 jan. 2017.
} 
histórico ou cultural; o V, que tem como base o acesso público à cultura, à educação e à ciência; por fim, o de número $\mathrm{X}$, que aponta para o combate a situações de pobreza e marginalização, e também à integração desses indivíduos menos favorecidos financeiramente.

Tendo em mente esses quatro (4) pontos, percebe-se que não há a específicidade, uma vez que não cita a palavra "paleontológico" ou "fósseis", mas há o destaque somente a sítios arqueológicos, que, conforme Silva (2015), são compostos por vestígios da cultura humana e não da natureza, com o qual estamos trabalhando. Isso pode atenuar o próprio tópico IV da lei local, pois, por meio de uma ausência, dá margem às problemáticas a serem combatidas (p.e. GADENSMARCON; OLIVEIRA; VENERAL, 2014).

Martins (2009), ao abordar o conteúdo paleontológico da cidade de Santa Maria - RS, aponta para a falta de atenção do poder público e das instituições educacionais no que se refere ao estímulo das relações entre patrimônio paleontológico e os indivíduos que o rodeiam e/ou o vivenciam. Em vista disso, chega-se ao segundo princípio destacado anteriormente: o exemplo do Rio Grande do Sul.

Nesse caso, destacado por Castro (2009), o estado do Rio Grande do Sul, a partir da ausência de leis federais específicas, organizou-se para formular a lei estadual de número 11.738, de 13 de dezembro de 2001, que compreende as áreas fossilíferas ao defini-las, organizar normas de coletas, transporte, salvaguarda e ações sobre os fósseis, colaborando, de alguma maneira, para diminuir crimes contra esse patrimônio, como a depredação e a comercialização ilegal, que muito ocorrem em vários lugares do Brasil, devido à falta de políticas públicas, muitas vezes argumentadas pela ausência de estrutura e recursos financeiros.

Salinópolis pode tomar esse caso para si, pois possui um rico conteúdo fossilífero, que, como apresenta essa pesquisa, é pouco divulgado para o público belenense, porém, que possui relações como a do colecionismo local (p.e. OLIVEIRA JÚNIOR, 2014), que podem ser estudadas, uma vez que possuem uma formação preocupada com as mais diversas formas de relação entre sociedade e patrimônio, dando base para a criação de uma lei específica, que, diferente do exemplo citado, poderá partir de compreensões científicas sobre fósseis, mas também populares, uma vez que os pesquisadores devem dar espaço para os diferentes olhares e significados que as pessoas atribuem a sua realidade (CHAGAS, 2009; GADENS-MARCON, OLIVEIRA, VENERAL, 2014; MENDES, 2013; TOLENTINO, 2016).

Além disso, o município, principalmente a Praia do Atalaia, sofre com o excesso de 
carros, de pessoas e com a expansão de grandes hotéis, uma vez que é um dos destinos preferidos de turistas, principalmente durante no mês de julho, quando ocorrem as férias (RANIERI; ELROBRINI, 2016). É nesse momento que, no subtítulo a seguir, adentramos na possibilidade de implantação, a médio e longo prazo, de um museu para a região, uma vez que, no que se refere à economia local, os fósseis não têm sido vistos como uma possibilidade legal e sustentável de geração de renda (p.e. OLIVEIRA JÚNIOR, 2014).

\section{O Museu de Paleontologia de Salinópolis como um meio de salvaguarda e renda sustentável}

Nesse momento, podem-se relembrar os pontos V e X da Portaria n ${ }^{\circ}$ 34/2011, de 29 de setembro de 2011, que, em suma, atentam para a importância de disponibilizar para a comunidade local, o acesso à cultura, à educação e à ciência, e de combater as situações de pobreza e marginalização através da integração de indivíduos menos favorecidos financeiramente. Essas competências vão ao encontro às intituições museológicas, haja vista que ao serem constituídas, caminham em meio a contextos políticos, culturais, sociais e econômicos do cotidiano humano (LIMA; GUIMARÃES, 2011).

De acordo com Lima e Guimarães (2011), os museus se caracterizam como locais de educação, lazer e turismo, podendo promover o repasse do conhecimento, valorização da memória e da comunidade que os rodeiam, por meio de uma atitude comum da humanidade: a ação de guardar coisas! Guardar documentos e objetos dá a oportunidade de compreender algo que se passou e, no caso de espaços como os museus, deve-se desenvolver não somente o acondicionamento, mas também o ensino e a exposição de sua coleção, para que as pessoas possam ter acesso a informações organizadas, sobre as transformações que o mundo passou, assim como de seus testemunhos.

Pode-se dizer que essas ações fazem parte de um processo chamado de musealização (p.e. LOUREIRO, 2016; MAROEVIC, 2001; SANTOS, LOUREIRO, 2012), que, em relação ao patrimônio paleontológico, em tese, é realizado na capital Belém, por meio do Museu Paraense Emílio Goeldi (MPEG), que conta com fósseis também adquiridos através de coletas na Praia do Atalaia (p.e OLIVEIRA JUNIOR, 2014).

É por meio dessa atuação que vemos o Museu Paraense Emílio Goeldi (MPEG) como um importante participante do processo de implementação de uma instituição de salvaguarda na região, 
pois junto à prefeitura do município, pesquisadores da área da Museologia e da comunidade local, pode contribuir para o debate ao compartilhar de sua trajetória e experiências relacionadas ao patrimônio paleontológico paraense, formando, então, um espaço pautado em leis e compreensões populares e científicas (PÁSSARO, HESSEL, NOGUEIRA NETO, 2014; SANJAD, 2007).

Tendo em mente que, segundo Carvalho e Rosa (2008), a melhor maneira de salvaguardar o patrimônio paleontológico é demonstrar para a comunidade, como os fósseis podem ser trabalhados na economia local, o museu, a ser implantado, pode fomentar a salvaguarda e a divulgação fossilífera, e também a geração sustentável de renda para a população do município, considerando os impactos turísticos negativos que recebe a Praia do Atalaia, e que as próximas gerações devem ter também a possibilidade de acessar esse conteúdo atualmente presente em nossa realidade (LIMA, GUIMARÃES, 2011; RANIERI, EL-ROBRINI, 2016; SANTOS, CARVALHO, FERNANDES, 2010).

Sustentabilidade ligada a museus, conforme Filipe (2011), apresenta os contextos ambientais, sociais, econômicos e culturais como quatro grandes e interessantes pilares que devem interagir entre si e promover a participação das pessoas, em pról de um bem-estar contínuo, durável e de qualidade, e que no caso de Salinópolis, pode-se pautar por meio de propostas e ações museológicas e sustentáveis já existentes.

Como exemplo, temos o caso da Chapada do Araripe, que sofre bastante com o comércio ilegal de fósseis, atenuado pela legislação e debilidade econômica existente na região (SANTOS; CARVALHO; FERNANDES, 2010). A localidade conta com o Geopark Araripe, criado por meio de uma parceria entre o Governo do Estado do Ceará e a Universidade Regional do Cariri (URCA), e possui coordenação, conselho de gestão com instituições, poderes públicos municipal, estadual e federal, pesquisadores com diversas formações acadêmicas pela própria URCA e também de outras universidades, e o Museu de Paleontologia da URCA, que procuram melhorar a vida da população por meio da promoção de uma sustentabilidade com atividades científicas, culturais, turísticas e econômicas, as quais abraçam, principalmente, as escolas (VILAS-BOAS; BRILHA; LIMA, 2013).

Apesar disso, Vilas-Boas, Brilha e Lima (2013) propõem ações para o Geopark Araripe, que dependem da interação entre instituições federais e estaduais (e por que não, municipais, tal como defendemos nesse trabalho?), que podem ser aplicadas em outras regiões fossilíferas brasileiras, como Salinópolis, desde que possuam modificações caso necessário. 
Os autores apresentam dois modelos de propostas educacionais com o patrimônio paleontológico, que podem ser reconsideradas para um museu em Salinópolis, são elas:

1) Formais: Focada na realização de minicursos, com professores locais de Ciências e de Geografia, a modo de apresentar desde a paleontologia e geologia da região, até as ideias de patrimônio e sua conservação.

2) Informais: Concentrada em atender a comunidade local e os transeuntes sem comprometer o ambiente da região, por meio de exposições itinerantes dos fósseis em pontos de grande visitação e em escolas; do reconhecimento público a pessoas que encontrarem, coletarem e doarem esses vestígios ao museu local; com a elaboração de jogos virtuais no site da instituição e premiação simbólica alusiva ao museu; promoção de coletas educativas, para mostrar à comunidade, seus estudantes, colecionadores locais e turistas, como agir após encontrar e coletar um fóssil.

Abordando a mesma localidade, Soares et al. (2014) aponta, também, para a importância de reprodução de réplicas dos fósseis, pois podem se caracterizar como material de ensino, alternativa economicamente sustentável de comercialização pela população de pouco poder aquisitivo, e até mesmo como conteúdo complementar para as coleções particulares locais. Além disso, o Museu, por meio de seus profissionais, pode utilizar, em suas atividades, materiais e/ou equipamentos adquiridos junto aos comerciantes locais, gerando renda indireta para esses indivíduos (p.e OLIVEIRA JUNIOR, 2014).

Todas essas acões exemplificadas podem ser, inicialmente, realizadas por um possível Museu de Paleontologia em Salinópolis, e depois ampliadas, sempre de forma distribuída entre poder público, instituições, profissionais da área da Museologia e sociedade, em prol do patrimônio paleontológico do município, levando em consideração que um bom museu atrai grandes pesquisadores, público, interesses dos meios de comunicação e informação, e investimentos em exposições e eventos, que, em conjunto, podem valorizá-lo junto à comunidade local e transeunte, fazendo-o ter perspectivas reais de crescimento no campo social e museal (DELPHIM, 2009; KELLNER, 2005).

\section{CONCLUSÃO}


Refletindo os dados obtidos, conclui-se que, em meios físicos e virtuais, há informações sobre a Formação Pirabas, porém, de forma tímida, a julgar que instituições de pesquisas pioneiras, como o Museu Paraense Emílio Goeldi (MPEG) e a Biblioteca Pública Arthur Vianna (BPAV), principal biblioteca da cidade de Belém, trazem consigo o papel de divulgar e informar os melhores usos para os patrimônios presentes na Amazônia.

Deve-se, também, considerar que disponibilizar informações não significa necessariamente que determinados indivíduos irão acessá-las, haja vista que, em variadas situações, devido ao contexto educacional e econômico no qual alguns sujeitos possam se encontrar, deve-se haver o estímulo à pesquisa de temas que, a priori, podem não ser de interesse algum para esses grupos. É considerando esse cenário que os meios de comunicação, assim como museus e bibliotecas, devem se engajar mais ainda, disponibilizar mais conteúdo, sobressair-se a possíveis situações que possam causar esse desinteresse, contribuindo para o desenvolvimento, reflexão crítica e aprendizagem dos usos e formas de salvaguarda desse patrimônio.

No que se refere às entrevistas, percebe-se que o conhecimento o qual parte da população do centro urbano possui sobre o patrimônio paleontológico do estado, apresenta-se de maneira retraída, a julgar que menos de $35 \%$ dos entrevistados consideram bens de cunho geológico como patrimônio. Fato que se evidencia quando abordamos, especificamente, um sítio fossilífero, como a Praia do Atalaia, em Salinópolis, a partir do momento em que a maioria das respostas não apresentam precisão e, em alguns casos, são confusas, pois em vez de locais compostos por vestígios fósseis, são pontuadas áreas de registros arqueológicos, indicando incertezas quanto ao objeto de estudo de duas ciências distintas.

Sendo assim, conclui-se que não há uma relação consistente entre homem e patrimônio paleontológico no centro urbano de Belém, afinal são divulgadas poucas informações para o público, gerando um desconhecimento que intervém diretamente no usufruto sócio-cultural desses bens e num possível desenvolvimento econômico da região que o detém.

Cabe-se, também, o destaque para a elaboração de uma lei que considere as apreenções científicas e populares, uma vez que há relações singulares, como o colecionismo de fósseis; e de um museu para o município de Salinópolis, que possa impulsionar a participação e novas formas de geração de renda para a comunidade local, sem comprometer a presença desses vestígios para as futuras gerações. 
Por fim, este trabalho dá margem a outras futuras pesquisas orientadas para a população local de Salinópolis, partindo do pressuposto de que os fósseis, enquanto patrimônio, podem ser visualizados não somente como ferramentas de combate a baixos indices sociais, mas também a danos ambientais e interesses de grandes empresários, que, desarmonicamente, sobreponham-se à conservação de uma paisagem destacada por conter a história do principal e mais visitado balneário do estado do Pará.

\section{REFERÊNCIAS}

AGUIAR, Victor Laurenciano; MEDEIROS, Claudio Melquiades. Entrevistas na pesquisa social: o relato de um grupo de foco nas licenciaturas. In: CONGRESSO NACIONAL EDUCAÇÃO, EDUCERE, 9, 2009, Curitiba. Anais [...]. Curitiba PUCPR, 2009. p. 10710-10718.

BARBOSA, Maria Marthá. Moluscos miocênicos de Gerôncio, rio Urindeua e farol do Atalaia (estado do Pará). Boletim do Museu Nacional, Nova Série Geologia, n. 28 p. 1-27, 1958.

BARRETO, Alcina Franca et al. Difusão cultural para valorização e preservação do Patrimônio Paleontológico dos municípios de Tacaratue Petrolândia, Sertão Pernambucano, NE do Brasil. Estudos Geológicos. Série B, Estudos e Pesquisas (UFPE), v. 23, n. 1, p. 77-85, 2013.

BENTO, Lilian Moreira; RODRIGUES, Silvio Carlos. O geoturismo como instrumento em prol da divulgação, valorização e conservação do patrimônio natural abiótico - uma reflexão teórica. Turismo e paisagens cársticas, Belo Horizonte, v. 3, n. 2, p. 55-65, 2010.

BEVORT, Evelyne; BELLONI, Maria Luiza. Mídia educação: conceitos, história e perspectivas. Educação e Sociedade, Campinas, v. 30, n. 109, p. 1081-1102, set./dez. 2009.

BEZERRA, Márcia. As Moedas dos Índios?: um estudo de caso sobre os significados do patrimônio arqueológico para os moradores da Vila de Joanes, Marajó, Brasil. Boletim do Museu Paraense Emílio Goeldi, Ciências Humanas , v. 6, n. 1, p. 57-70, 2011.

BRILHA, José Bernardo. A Geologia, os Geólogos e o Manto da Invisibilidade. Comunicação e Sociedade, v. 6, p. 257-265, 2004.

BRITTO, Rosângela Marques de. Desafios na formação do museólogo frente à demanda social dos museus da região amazônica. In: SEMINÁRIO DE INVESTIGAÇÃO EM MUSEOLOGIA DOS PAÍSES DE LÍNGUA PORTUGUESA E ESPANHOLA, 2010, Portugal. Anais do ICOM. Faculdades de Letras Universidade do Porto: ICOFOM, 2010. Disponível em: http://ler.letras.up.pt/uploads/ficheiros/10327.pdf. Acesso em: 31 out. 2018.

CARVALHO, Ismar de Souza; ROSA, Átila Stock da. Patrimônio Paleontológico no Brasil: Relevância para o desenvolvimento sócio-econômico. Memórias e notícias, Coimbra, p. 15-28, 
2008.

CASSETTARI, Bruna de Oliveira. Paleontologia e evolução em revista popular de divulgação científica e suas implicações para o ensino de biologia. 2011. 29 f. Trabalho de Conclusão de Curso (Bacharelado - Ciências Biológicas) - Universidade Estadual Paulista, Instituto de Biociências de Botucatu, SP.

CASTRO, Aline Rocha de Ferreira de. Geoconservação e Musealização: a aproximação entre duas visões de mundo. Os múltiplos olhares para um patrimônio. 2009. 155 f. Dissertação (Mestrado em Museologia e Patrimônio) - Universidade do Rio de Janeiro, RJ.

CASTRO, Aline Rocha de Ferreira de; CARVALHO, Ismar de Souza. Reflexões preliminares sobre as contribuições da Museologia ao estudo do Patrimônio Geológico. In: $46^{\circ}$ CONGRESSO BRASILEIRO DE GEOLOGIA, 2012, Santos. 46 CONGRESSO BRASILEIRO DE GEOLOGIA. Anais eletrônicos [...].Santos: Sociedade Brasileira de Geologia, 2012. Disponível em: http://www.sbgeo.org.br/home/pages/44. Acesso em: 31 out. 2018.

CASTRO, Aline Rocha de Ferreira de; MANSUR, Kátia Leite; CARVALHO, Ismar de Souza. Diagnóstico da relação da comunidade com o patrimônio geológico por meio de instrumento de coleta de dados. Terra e Didática, São Paulo, n. 3, 2015. Disponível em: http://www.ige.unicamp.br/terraedidatica/. Acesso em: 04 jan. 2018.

CHAGAS, Mário de Souza. Memória e poder: dois movimentos. Cadernos de Sociomuseologia, América do Norte, 19, jun. 2009.

COSTA, João Batista Sena et al. Neotectônica da região amazônica: aspectos tectônicos, geomorfológicos e deposicionais. Revista Geonomos, Minas Gerais, v. 4, n. 2, p. 23-43, dez. 1996.

COSTA, Sue Anne Regina Ferreira da; TOLEDO, Peter Mann de; MORAES-SANTOS, Heloisa Maria. Paleovertebrados. In: ROSSETTI, Dilce de Fátima; GÓES, Ana Maria (Eds.). O Neógeno da Amazônia Oriental. Belém: Museu Goeldi, v. 1. p. 135-166, 2004.

DELPHIM, Carlos Fernando de Moura. Patrimônio cultural e Geoparque. Geologia USP, São Paulo, v. 5, p. 75-83, 2009.

DIAS, Graciete et al. Contribuição para a valorização e divulgação do património geológico com recurso a painéis interpretativos: exemplos em áreas protegidas do NE de Portugal. Ciências da Terra, Portugal, n. 5, 2003. http://repositorium.sdum.uminho.pt/bitstream/1822/1256/1/cng_dias.pdf. Acesso em: 31 out. 2018.

DRESCH, Rafael Valle. Breves Apontamentos Sobre a Proteção Legal ao Patrimônio Paleontológico. Paleontologia em Destaque, Porto Alegre, n. 56, dez. 2006. Disponível em: http://www.sbpbrasil.org/boletim//. Acesso em: 23 dez. 2017. 
EHRENBERG, Karla Caldas; GALINDO, Daniel dos Santos. Os jovens consumidores conectados e o mobile marketing. 2010. Disponível em: http://www.ipea.gov.br/panam/pdf/GT2_Art5_Karla.pdf. Acesso em: 05 jan. 2018.

FERREIRA, Cândido Simões; CUNHA, Osvaldo Rodrigues. Contribuição à Paleontologia do Estado do Pará. Novos invertebrados fósseis e redescrições de mais duas espécies da formação Pirabas. III. (Mollusca-Gastropoda). Boletim do Museu Paraense Emílio Goeldi, nova série Geologia, n. 4, p. 1- 33, 1957.

FILIPE, Graça. O poder dos museus: reflectindo sobre as missões e a sustentabilidade dos museus, em teoria e na prática. In: ENCONTRO MUSEUS E SUSTENTABILIDADE FINANCEIRA, 2011, Museu Nacional Soares Reis, Portugal. Anais eletrônicos [...]. Portugal, 2011. Disponível em: http://icomportugal.org/multimedia/Ficheiros/Filipe_\%20G_\%200\%20poder\%20dos\%20museus.pdf. Acesso em: 31 out. 2018.

GADENS-MARCON, Gabrielli Teresa; OLIVEIRA, Sônia de; VENERAL, Débora Cristina. O direito ambiental de proteção ao patrimônio natural e científico no Brasil com ênfase no patrimônio paleontológico. Ius Gentium, v. 8, n. 5, p. 35-58, 2014.

GESICKI, Ana Desenzi; SANTUCCI, Rodrigo Miloni. Mineração e geoconservação: O sítio paleontológico de Santa Rosa de Viterbo, SP. Revista Instituto de Geologia, São Paulo, v. 32, n. 1-2, p. 41-53, 2011.

GREGORIO, Anderson da Silva; MENDES, Amilcar Carvalho; BUSMAN, Débora Vieira. Morfodinâmica da Praia do Atalaia, Salinópolis, NE do Pará. In: X CONGRESSO DA ASSOCIAÇÃO BRASILEIRA DE ESTUDOS DO QUATERNÁRIO, 2005, Guarapari/ES. Anais eletrônicos $\quad[\ldots] . \quad$ Guarapari/ES, $2005 . \quad$ Disponível em: http://www.abequa.org.br/trabalhos/0013_aderson_abequa2005.pdf. Acesso em: 31 out. 2018.

GUIMARÃES, Nathália Arruda. A proteção do patrimônio cultural: uma obrigação de todos. Revista Jus Navigandi, Teresina, ano 9, n. 354, 26 jun. 2004. Disponível em: https://jus.com.br/artigos/5372. Acesso em: 4 jan. 2018.

GUIMARÃES, Claudio Jorge; LIMA, Lauren Prestes. Interatividade em Museus e Sustentabilidade Cultural. In: V FÓRUM INTERNACIONAL DE TURISMO DO IGUASSU, 2011, Foz do Iguaçu. Anais eletrônicos [...]. Foz do Iguassu, 2011. Disponível em: http://festivaldeturismodascataratas.com/wp-content/uploads/2014/01/8.-INTERATIVIDADEEM-MUSEUS-E-SUSTENTABILIDADE-CULTURAL.pdf. Acesso em: 31 out. 2018.

JURBERG, Claudia; GOUVEIA, Maria Emmerick; SOUSA, Camila Belisário. Na mira do câncer: o papel da mídia brasileira. Revista Brasileira de Cancerologia, Rio de Janeiro, v. 52, n. 2, p. 139-146, Jan. 2006.

KALIFE, Kalília dos Reis. Mineração de calcário no município de Capanema, estado do Pará: uma análise a partir da percepção dos moradores do entorno da Jazida B-17. 2013. 118 f. 
Dissertação (Mestrado em Planejamento do Desenvolvimento) - Programa de Pós Graduação em Desenvolvimento Sustentável do Trópico Úmido (PDTU), do Núcleo de Altos Estudos Amazônicos, Universidade Federal do Pará, Belém, PA.

KAMPF, Cristiane. A geração Z e o papel das tecnologias digitais na construção do pensamento. ComCiência, Campinas, n. 131, 2011. Disponível em: http://comciencia.scielo.br/pdf/cci/n131/a04n131.pdf. Acesso em: 05 jan. 2018.

KELLNER, Alexander Wilhelm Armin. Museus e a divulgação científica no campo da paleontologia. Anuário do Instituto de Geociencias - UFRJ, Rio de Janeiro, v. 28, n. 1, p. 116$130,2005$.

LOUREIRO, Maria Lúcia de Matheus. Reflexões sobre Musealização: processo informacional e estratégia de preservação. In: III SEMINÁRIO SERVIÇOS DE INFORMAÇÃO EM MUSEUS, 2016, São Paulo. Anais eletrônicos [...]. São Paulo: Pinacoteca de São Paulo, 2016. Disponível em: http://biblioteca.pinacoteca.org.br:9090/publicacoes/index.php/sim/article/view/76. Acesso em: 31 out. 2018.

MACHADO, Rodrigo. Políticas públicas para a proteção do patrimônio fossilífero brasileiro. 2008. 52 f. Dissertação (Especialização em Gestão Pública) - Programa de Pós Graduação Lato Sensu em Gestão Pública, da Universidade Candido Mendes, Rio de Janeiro, RJ.

MAROEVIC, Ivo. O Papel da Musealidade na preservação da memória. In: SCHEINER, Tereza Cristina Moletta. Caderno de textos da disciplina Museologia 01 - Bases teóricas da Museologia. 2001.

MARTINS, José da Silva. Educação patrimonial dos sítios paleontológicos da Formação Santa Maria - RS: Memórias da Cidade Estudo com alunos do Ensino Fundamental. 2009. 100 f. Dissertação (Mestrado em Educação) - Universidade Federal de Santa Maria (UFSM), Programa de Pós-Graduação em Educação, Santa Maria, RS.

MENDES, Manuel Cardoso. Museus e Sustentabilidade Ambiental. Museologia e Patrimônio, Rio de Janeiro, v. 6, p. 71-97, 2013.

NASCIMENTO, Marcos Antonio Leite do; RUCHKYS, Úrsula de Azevedo; MANTESSO NETO, Virgínio. Geodiversidade, Geoconservação e Geoturismo: trinômio importante para a proteção do patrimônio geológico. São Paulo: Sociedade Brasileira de Geologia, 2008.

OLIVEIRA JUNIOR, Emanoel Fernandes de. Por onde o Mar passou: A relevância de se Musealizar in situ os Afloramentos Fossilíferos da Praia do Atalaia, em Salinópolis - PA. 2014. 96 f. Trabalho de conclusão de curso (Graduação em Museologia) - Universidade Federal do Pará, Belém, PA.

PÁSSARO, Eloísa Magalhães; HESSEL, Maria; NOGUEIRA NETO, José de Araújo. Principais acervos de paleontologia do Brasil. Anuário do Instituto de Geociências -UFRJ, v. 37, p. 4859, 2014. 
PENNA, Domingos Ferreira. Breve notícia sobre os sambaquis do Pará. Arquivos do Museu Nacional, $\quad$ v. $\quad 1, \quad$ p. 85-89, 1876. Disponível em: http://museunacional.ufrj.br/publicacoes/?page_id=190. Acesso em: 31 out. 2018.

PEREIRA, Edithe. Arqueologia ao alcance de todos - a difusão da pesquisa arqueológica de Monte Alegre - Pa. Ver a Ciência - Revista de Ciência, Tecnologia e Inovação do Estado do Pará, Belém, p. 20-25, abr. 2014.

PIRES, Erik de Nazaré; GIRARD, Carla Teixeira. O Foursquare como ferramenta de marketing: uma análise sobre a Biblioteca Central da Universidade Federal do Pará (UFPA). Revista ACB (Florianópolis), v. 16, p. 89-101, 2014.

PONCIANO, Luiza Corral de Oliveira; MACHADO, Deuseana da Costa; CASTRO, Aline de Rocha Ferreira de. Patrimônio paleontológico. In: SOARES, Marina Bento (Org.). Livro Digital de Paleontologia: a paleontologia na sala de aula. 2. ed. Ribeirão Preto: Sociedade Brasileira de Paleontologia, 2013. p. 460-472.

PORTO, Cristiane de Magalhães; BROTAS, Antonio Marcos; BORTOLIERO, Simone Terezinha. Diálogos entre ciência e divulgação científica: leituras contemporâneas. Salvador: EDUFBA, 2011. 242p.

RAMOS, Andrade. Os paleontólogos brasileiros. Anuário do Instituto de Geociencias - UFRJ, Rio de Janeiro, v.10, p. 126-140, 1986.

RANIERI, Leilanhe; EL-ROBRINI, Maâmar. Condição Oceanográfica, Uso e Ocupação da Costa de Salinópolis (Setor Corvina - Atalaia), Nordeste do Pará, Brasil. Revista da Gestão Costeira Integrada, Portugal, v. 16, n. 2, 2016.

RIBEIRO, Ana Maria; IANNUZZI, Roberto. Legislação de Proteção ao Patrimônio Fossilífero Brasileiro. Boletim da Associação Latino Americana de Paleobotânica e Palinologia, n. 13, p. 09-16, 2009.

SANJAD, Nelson. O lugar dos museus como centros de produção de conhecimento científico. In: BITTENCOURT, José Neves; GRANATO, Marcus; BENCHETRIT, Sarah F. (Org.). Museus, ciência e tecnologia. Rio de Janeiro: Museu Histórico Nacional, 2007. p. 123-133.

SANTOS, Alexandre dos. Os hábitos do novo público-leitor, do antigo jornal impresso: Caso Gazeta do Povo. Temática, João Pessoa, v. 11, 2010. Disponível em: http://www.insite.pro.br/2010/novembro/habitos_leitor_jornalimpresso.pdf. Acesso em: 05 jan. 2018.

SANTOS, Wellington Francisco dos; CARVALHO, Ismar de Souza. A preservação do patrimônio geológico e paleontológico em Peirópolis-Uberaba (Minas Gerais): contribuição para o desenvolvimento sócio espacial. Anuário do Instituto de Geociencias - UFRJ, Rio de Janeiro, v.30, n.1, p. 254-254, 2007. 
SANTOS, Wellington Francisco dos; CARVALHO, Ismar de Souza; FERNANDES, Antonio Sequeira. Mineração versus Paleontologia: uso e ocupação da serra do Veadinho em PeirópolisUberaba, Estado de Minas Gerais (Brasil). Anuário do Instituto de Geociencias - UFRJ, Rio de Janeiro, v. 33, n. 2, p. 74-86, 2010.

SANTOS, Rodrigo Pereira dos; ESTERCI, Neide. O ambiente e o desenvolvimento sob a perspectiva da mudança social. Caderno CRH. Salvador, v. 29, p. 203-208, maio/ago. 2016.

SANTOS, Liliane Bispo do; LOUREIRO, Maria Lúcia de Matheus. Musealização como estratégia de preservação: Estudo de Caso sobre um previsor de marés. Museologia e Patrimônio, Rio de Janeiro, v. 5, p. 49-67, 2012.

SCHOBBENHAUS, Carlos; SILVA, Cassio Roberto da. O Papel do Serviço Geológico do Brasil na Criação de Geoparques e na Geoconservação do Patrimônio Geológico. In: SCHOBBENAUS, Carlos; SILVA, Cassio Roberto da (Org.). Geopaques do Brasil: proposta. Rio de Janeiro: CPRM-Serviço Geológico do Brasil, 2012. v. 1, p. 11-28.

SCIFONI, Simone. A construção do patrimônio natural. 2006. 294p. Tese (Doutorado em Geografia Humana) - Faculdade de Filosofia, Letras e Ciências Humanas, Universidade de São Paulo, São Paulo, SP.

SEFIDVASH, Farhang. O papel da universidade na transformação da sociedade. In: II CONGRESSO DE EDUCAÇÃO PARA INTEGRAÇÃO DA AMÉRICA LATINA INTEGRAÇÃO E CIDADANIA, 1994, Maringá. Anais eletrônicos [...]. Paraná, 1994. Disponível em: http://www.sefidvash.net/publications/78\%20)\%200\%20papel\%20Da\%20UNiversidade\%20.pd f. Acesso em: 31 out. 2018.

SIEBRA, Sandra Albuquerque; OLIVEIRA, Júccia do Nascimento; MARCELINO, Críssia de Santana. Avaliação do Acesso e Visualização da Informação em Repositórios Institucionais. Informação \& Tecnologia, Marília/João Pessoa, v. 1, n. 2, p. 77-95, jul./dez. 2014.

SILVA, Paulo Gracino da. Arqueologia e Paleontologia: os pontos básicos que caracterizam estas duas Ciências distintas. Revista tarairiú, Campina Grande, v. 01, n. 9, p. 58-68, fev. 2015.

SILVA, Gerson Santos e. Encantados da "Fortaleza" insular: D. Sebastião, natureza em uma história cultural na Amazônia. 2007. 172 p. Dissertação (Mestrado em História Social da Amazônia) - Universidade Federal do Pará (UFPA), Programa de Pós-Graduação em História Social da Amazônia, Belém, PA.

SILVA, Augusto Fantinei da; BARRETO FILHO, Abdon. A influência da mídia no turismo paleontológico da cidade de Mata/RS nos anos de 2010 e 2011. In: $2^{\circ}$ SEMINÁRIO DE PESQUISA EM TURISMO JR., 2011, Caxias do Sul. Anais eletrônicos [...]. Rio Grande do Sul, 2011. Disponível em: https://www.ucs.br/site/midia/arquivos/03_a_proposta_de_projeto.pdf. Acesso em: 31 out. 2018. 
SILVA, Leonardo de Souza; SILVA, Rayana Alexandra Sousa da; COSTA, Sue Anne Regina Ferreira da. Afloramentos fossilíferos da Praia do Atalaia: A importância da mídia para a (re)construção de um discurso. In: II Seminário Brasileiro de Museologia, 2015, Recife. Anais II Sebramus. $2015 \mathrm{a}, \quad$ v. $2 . \quad$ p. $144 . \quad$ Disponível em: https://www.dropbox.com/s/2zrfzolck9y9sub/VOLUME\%205.pdf?dl=0. Acesso em: 29 out. 2018.

SILVA, Leonardo de Souza; SILVA, Rayana Alexandra Sousa da; COSTA, Sue Anne Regina Ferreira da. A construção do discurso da mídia de massa impressa sobre o patrimônio paleontológico paraense: Análise da divulgação da Praia do Atalaia e Jazida B-17. In: III Simpósio Brasileiro de Patrimônio Geológico, 2015, Lençóis - Chapada Diamantina. Anais III GeoBRheritage. 2015b. Disponível em: https://www.academia.edu/15655972/Anais_do_III_SImp\%C3\%B3sio_Brasileiro_de_Patrim\%C 3\%B4nio_Geol\%C3\%B3gico?auto=download. Acesso em: 29 out. 2018.

SILVA, Sandra Siqueira da. A relação entre ciência e senso comum. Ponto Urbe, São Paulo, n. 9, dez. 2011. Disponível em: http://journals.openedition.org/pontourbe/359. Acesso em: 05 jan. 2018.

SOARES, Maria Bento. (Org.). A paleontologia na sala de aula. Ribeirão Preto: Sociedade Brasileira de Paleontologia, 2015. 714p.

SOARES, Marcelo de Oliveira et al. Percepção ambiental e Educação Patrimonial: Estudo de caso sobre a conservação do Patrimônio Paleontológico. Revista Brasileira de Ciências Ambientais, Rio de Janeiro, v. 33, p. 100-115, 2014.

SOUZA, Aline Rocha et al. Geoconservação: a preservação e valorização do patrimônio geológico. In: CARVALHO, Ismar de Souza et al. (Org.). Paleontologia: Cenários de Vida. Rio de Janeiro: Interciência, 2007. v. 2, p. 79-88.

SYMANSKI, Luís Pereira; GOMES, Denise Cavalcante. Mundos mesclados, espaços segregados: cultura material., mestiçagem e segmentação no sítio Aldeia em Santarém (PA). Anais do Museu Paulista.São Paulo, v. 20, n. 2, p. 53-90, 2012. Disponível em: http://www.scielo.br/pdf/anaismp/v20n2/a03v20n2.pdf. Acesso em: 31 out. 2018.

TAPSCOTT, Don. Geração Digital: A crescente e irreversível ascensão da geração net. Tradução Ruth Gabriela Bahr. São Paulo: Makron Books, 1999.

TÁVORA, Vladimir de Araújo; SANTOS, André Augusto Rodrigues dos; ARAÚJO, Raphael Neto. Localidades fossilíferas da Formação Pirabas (Mioceno Inferior). In: Bol. Mus. Pará Emilio Goeldi, Cienc. Nat., Belém, v. 5, n. 2, p. 207 - 224, maio/ago. 2010a.

TÁVORA, Vladimir de Araújo; SANTOS, André Augusto Rodrigues dos; NOGUEIRA NETO, Ignácio Loiola Alvares. Eventos biológicos da Formação Pirabas (Mioceno Inferior). Revista Brasileira de Geociências, v. 40, p. 256-264, 2010 b. 
TÁVORA, Vladimir de Araújo; SILVEIRA, Eric Sandro da; MILHOMEM NETO, João Marinho. Mina B-17, Capanema-PA - Expressivo Registro de uma Paleolaguna do Cenozóico Brasileiro. In: WINGE, Manfredo et al. (Org.). Sítios Geológicos e Paleontológicos do Brasil. Brasília: DNPM/CPRM - Comissão Brasileira de Sítios Geológicos e Paleobiológicos (SI-GEP), 2007. v. II, p. 0-8.

TOLEDO, Peter Mann de et al. Contribuição para a paleontologia no Estado do Pará. Presença de Crocodiliana Formacão Pirabas, Mioceno Inferior. Boletim do Museu Paraense Emílio Goeldi, Série Ciências da Terra, Belém, v. 9, p. 107-113,1997.

TOLEDO, Peter Mann de; DOMNING, Daryl. Fóssil de Sirenia (Mammalia: Dugongidae) da Formação Pirabas (Mioceno), norte do Brasil. Boletim do Museu Paraense Emílio Goeldi, Ser. Ciênc. Terra, v. 1, n. 2, p. 119-146, 1989.

TOLENTINO, Atila Bezerra. Museologia Social: apontamentos históricos e conceituais. Cadernos de Sociomuseologia, v. 52, p. 21-44, 2016.

UNESCO. Convenção sobre a Proteção do Patrimônio Mundial., Cultural e Natural. UNESCO, 1972.

VILAS-BOAS, Mariana; BRILHA, José Bernardo; LIMA, Flavia Fernanda de. Conservação do patrimônio paleontológico do geopark Araripe (Brasil): enquadramento, estratégias e condicionantes. Boletim Paranaense de Geociências, [S.1.], v. 70, dez. 2013.

Recebido em: 13 de junho de 2018

Aceito em: 30 de novembro de 2018 